\title{
OECDpublishing
}

\section{DISENTANGLING URBAN AND RURAL FOOD SECURITY IN WEST AFRICA}

\section{WEST AFRICAN PAPERS}

May 2018 No. 15

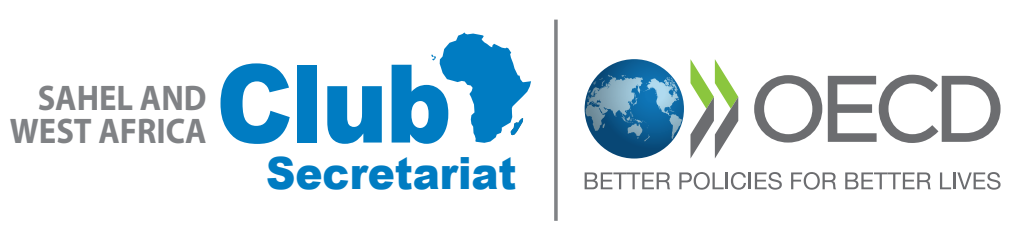





\section{DISENTANGLING URBAN AND RURAL FOOD SECURITY IN WEST AFRICA}

This paper has been prepared by

CORNELIA F.A. VAN WESENBEECK

Amsterdam Centre for World Food Studies, VU University 


\section{WEST AFRICAN PAPERS}

The West African Papers series explores African socio-economic, political and security dynamics from a regional and multidisciplinary perspective. It seeks to stimulate discussion and gather information to better anticipate the changes that will shape future policies. The series is designed for a wide audience of specialists, development practitioners, decision makers and the informed public. Papers are available in English and/or French, and summaries are available in both languages. Initiated by the Sahel and West Africa Club (SWAC) to highlight and promote West African issues, the work presented is prepared by its Secretariat, Members and partners, other OECD departments, related international organisations, associated experts and researchers.

Please cite this publication as:

van Wesenbeeck, Cornelia F.A. (2018), “Disentangling Urban and Rural Food Security in West Africa", West African Papers, N¹5, OECD Publishing, Paris.

https://doi.org/10.1787/e0c75266-en

Author contact: c.f.a.van.wesenbeeck@vu.nl

ISSN 2414-2026

OECD Working Papers should not be reported as representing the official views of the OECD or of its member countries. The opinions expressed and arguments employed are those of the authors.

This document and any map included herein are without prejudice to the status of or sovereignty over any territory, to the delimitation of international frontiers and boundaries and to the name of any territory, city or area.

Working Papers describe preliminary results or research in progress by the author(s) and are published to stimulate discussion on a broad range of issues on which the OECD works. Comments on Working Papers are welcomed, and may be sent to the Sahel and West Africa Club, OECD, 2 rue André-Pascal, 75775 Paris Cedex 16, France.

Authorised for publication by Laurent Bossard, Director, Sahel and West Africa Club Secretariat (SWAC/OECD).

You can copy, download or print OECD content for your own use, and you can include excerpts from OECD publications, databases and multimedia products in your own documents, presentations, blogs, websites and teaching materials, provided that suitable acknowledgment of OECD as source and copyright owner is given. All requests for commercial use and translation rights should be submitted to rights@oecd.org. 


\begin{abstract}
Strategies to fight hunger and early warning systems often focus on identifying food crises rather than longer-term trends, and concentrate on rural areas. Data on the food and nutrition security situation of West Africa's growing urban population is scarce and fragmented. Using geo-referenced information available in the Demographic and Health Surveys (DHS), this report estimates the total number and prevalence of under-nutrition and over-nutrition in West Africa for both urban and rural areas. The analysis reveals that almost 110 million people in West Africa are not receiving the correct nutrition for their needs. Over 58 million people in the region are underweight, 22 million of which live in cities.. Another 52 million are either overweight or obese, the large majority of whom are adult urban dwellers. This situation reveals the severity of the "double burden" of under- and over-nutrition. It also calls for greater efforts to identify appropriate metrics to monitor food and nutrition security in urban areas.
\end{abstract}

Keywords: Food security, nutrition, urban households, obesity, early warning systems

JEL Classification: Q18, R28, I32

\title{
ACKNOWLEDGEMENTS
}

The author would like to thank Thomas Allen, Lia Beyeler, Richard Clarke and Inhoi Heo for their valuable feedback, suggestions and edits.

THE SAHEL AND WEST AFRICA CLUB

The Sahel and West Africa Club (SWAC) is an independent, international platform.

Its Secretariat is hosted at the Organisation for Economic Co-operation and Development (OECD).

\section{Mission}

SWAC's mission is to promote regional policies that will improve the economic and social well-being of people in the Sahel and West Africa.

\section{Objectives}

- Improve the regional governance of food and nutrition security.

- Improve the understanding of ongoing transformations in the region and their policy implications through regional, spatial and forward-looking analyses.

\section{Members}

Austria, Belgium, Canada, CILSS, the ECOWAS Commission, the European Union, France, Luxembourg, the Netherlands, Switzerland, the UEMOA Commission and the United States.

The World Bank, the Nepad Planning and Co-ordination Agency and the Network of Farmers' Organisations and Agricultural Producers of West Africa are observers.

SWAC has memorandums of understanding with the NEPAD Agency and the University of Florida (Sahel Research Group).

For more information: http://www.oecd.org/swac. 


\section{TABLE OF CONTENTS}

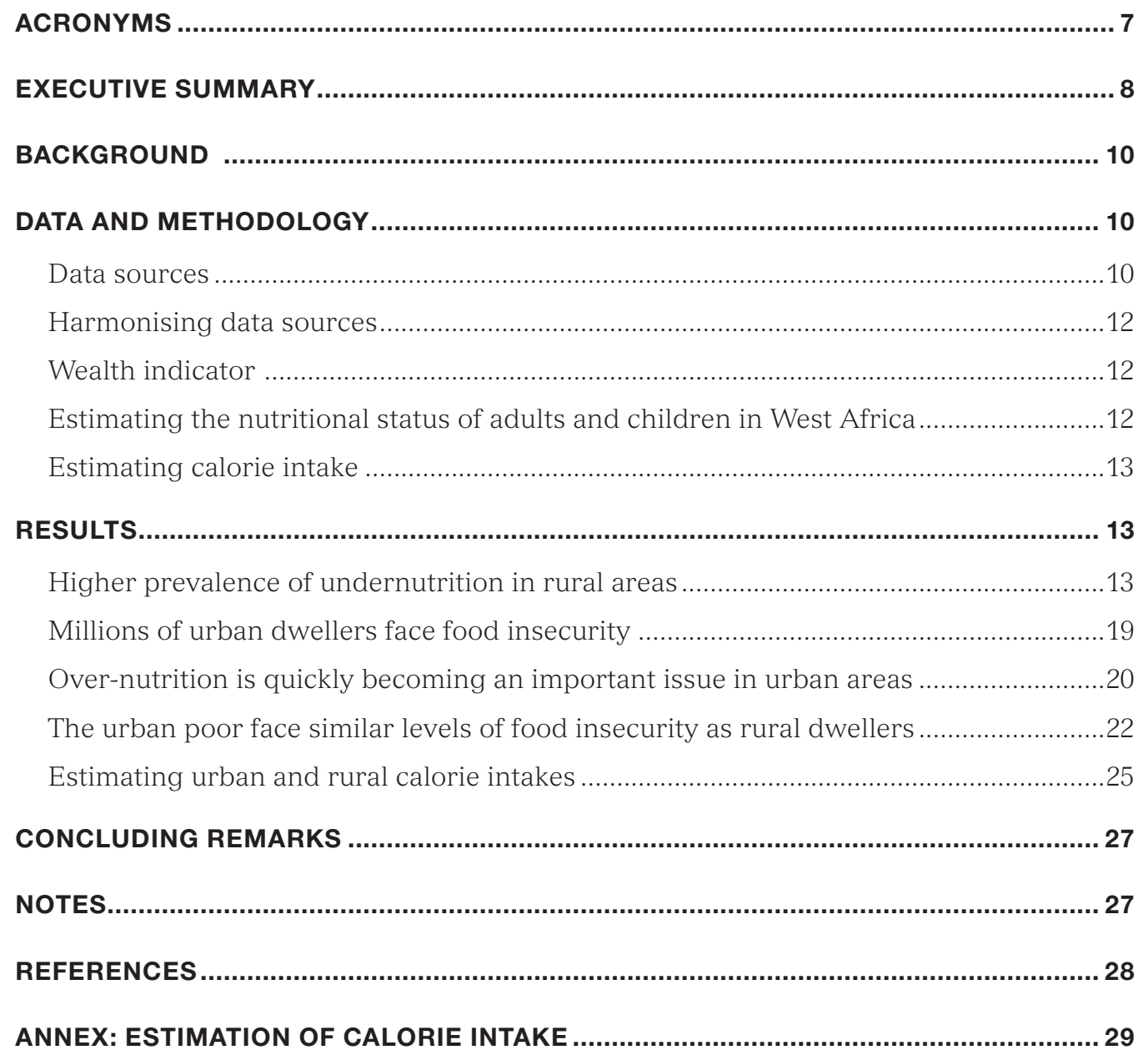




\section{ACRONYMS}

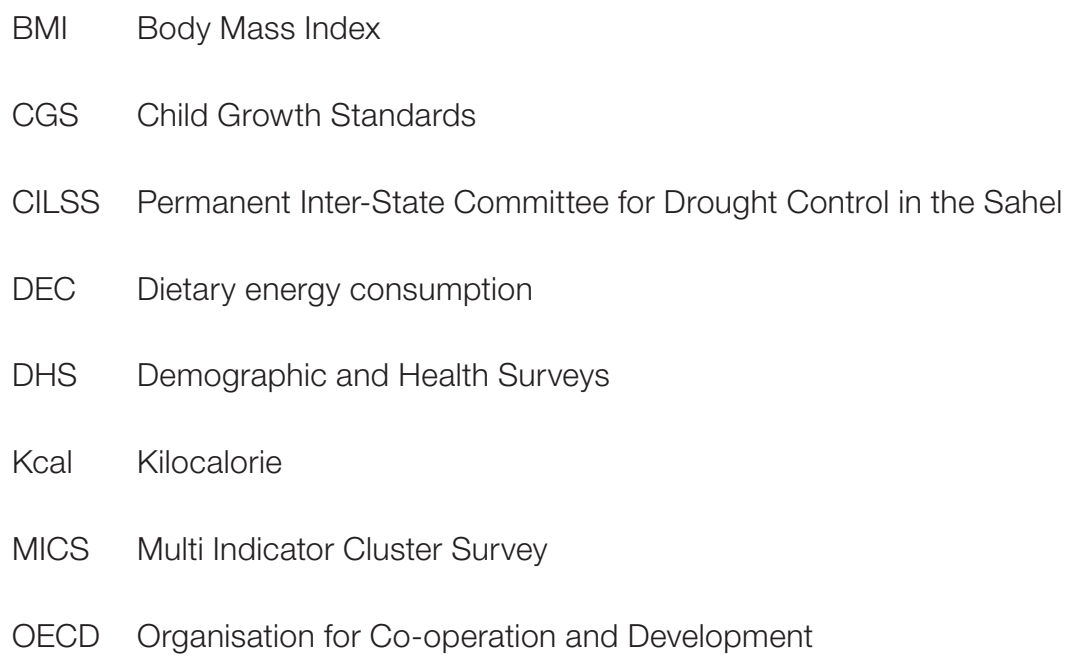




\section{EXECUTIVE SUMMARY}

$\mathrm{T}$ he international debate on strategies to fight hunger centres on headcounts of people below (or above) given nutritional standards. But for West African countries, there are relatively few accessible sources that provide internationally comparable estimates of people's nutritional status. The most widely used estimations, based on food availability, have received criticism, however, for being indirect and unable to accurately identify "hunger hot spots" where policy interventions, including food aid, are most required. Regionally-led approaches to identifying nutritional crises, such as the Cadre Harmonisé for West Africa (CILSS, 2016), have helped to address some of these challenges. Yet, there remains a dearth of indicators on long-term nutritional trends and food security issues arising in rapidly growing urban agglomerations.

This paper makes two significant contributions towards providing detailed disaggregated information on food and nutrition security in both rural and urban areas. Firstly, it estimates the total number and percentage of malnourished people living in West Africa's agglomerations by wealth quintile - both those that are over- and under-nourished using provincial- and district-level anthropometric information from the United States Agency for International Development's Demographic and Health Surveys (DHS) Program. Secondly, the paper estimates average calorie intakes in both rural and urban areas, based on the geo-referenced recorded weights of women and children from the same surveys. Collectively, these contribute to identifying the type and location of West Africa's food security challenges.

\section{Key findings}

- The analysis reveals that there are almost 110 million people living in West Africa who are not receiving the correct nutrition for their needs. Over 58 million people in the region are classified as underweight, while around 52 million are either overweight or obese. That $30 \%$ of the region's population are either under- or over-nourished shows the severity of the challenge this "double burden" imposes on West Africa's health systems, which are generally already overstretched.

- Noteworthy differences in the prevalence and absolute numbers of the food insecure are evident between rural and urban areas. Combining data for adults and children reveals that $18 \%$ of rural inhabitants in West Africa are classified as underweight, compared to $13 \%$ of the urban population. Chronic food insecurity is shown to be a major issue amongst children, with $21 \%$ of urban and $35 \%$ of rural children on average suffering from severe or moderate stunting. Acute food security, measured by the prevalence of wasting in children, is less severe, but still extensive.

- The reverse is evident for the overweight population: $23 \%$ of the region's adult city dwellers are overweight and additional $12 \%$ obese, in comparison to $13 \%$ and $4 \%$ of the rural population. However, the prevalence of overweight or obese children is similar in urban and rural areas (2.4\% and $2.5 \%$ of the respective populations).

- There is considerable cross-country variation behind the aforementioned regional aggregate statistics, both in the prevalence and absolute numbers of the under- and over-nourished, and differences between rural and urban areas. For example, in Burkina Faso, underweight prevalence ranges from $11 \%$ in urban areas to $22 \%$ in rural areas, while in Côte d'Ivoire the respective rates are $10 \%$ and $11 \%$. Similarly, in Ghana, the rates of obesity in urban and rural areas are $21 \%$ and $8 \%$ respectively, compared to $7 \%$ and $1 \%$ in Chad. Differences in country population are also important to recognise - Nigerians, for example, make-up $65 \%$ of West Africa's urban underweight population. 
- $\quad$ Clear trends appear when analysing nutrition status by wealth quintiles. Adult obesity is a problem of the rich, almost exclusively in urban areas, while under-nutrition is an issue faced by the poor, regardless of whether they live in rural or urban settlements.

- The poorest urban households are as likely as any living in rural areas to be severely or moderately underweight $(1.3 \%$ and $2.3 \%$, respectively, in cities compared to $1.3 \%$ and $2.5 \%$ on average in rural areas). The prevalence of severely stunted children is considerably higher in poor urban areas (14.6\%) than in rural areas (9.8\%).

- The paper also computes calorie intakes separately for urban and rural areas for the first time. The results clearly show that calorie intakes in urban areas are higher than in rural areas for all countries across West Africa and suggest that differences in the calorie gap - based on dietary energy consumption calculations - between urban and rural populations might not be widely different. These findings indicate that there might be a systematic bias in the estimations of the prevalence of undernourishment, which may simultaneously underestimate the number of underweight individuals in the region and the extent of overweight and obesity issues.

\section{Key recommendations}

- These findings highlight the importance of spatial and distributional approaches for assessing the prevalence of food insecurity issues across West Africa. In particular, the paper shows significant variations in the prevalence of under and over-nutrition across countries and between rural and urban settlements. Greater research efforts are therefore required to identify more appropriate metrics to monitor food and nutrition security issues in urban areas and identify emerging issues.

- Food and nutrition security indicators must be developed for urban areas and incorporated into regional monitoring frameworks. The focus to-date has largely been at the national-level or in rural areas only, but as this paper shows, the extent of food and nutrition insecurity in urban areas is not dissimilar to that in rural areas.

- Monitoring mechanisms should also seek to incorporate indicators on the prevalence of overweight and obese individuals in particular in urban settlements. 


\section{BACKGROUND}

$\mathrm{T}$ he international debate on strategies to fight hunger centres on headcounts of people below (or above) given nutritional standards. However, for estimates of people's nutritional status, few sources are accessible that provide internationally comparable data. For most West African countries, such data are only available for young children and women of reproductive age in the Demographic and Health Surveys (DHS) Program. ${ }^{1}$ These surveys have nationwide coverage and are widely used to assess the nutritional status and development of children, for example, by the United Nations Children's Fund (UNICEF) and the World Health Organisation (WHO). ${ }^{2}$ For national headcounts of undernourishment, the international community relies on an indirect measure developed by the United Nation's Food and Agricultural Organisation (FAO, 2017). This measure is obtained by distributing food availability - measured as production plus net imports at the national level ${ }^{3}$ - among household groups on the basis of information from household expenditure surveys. This calculation provides food availability by household group and can be compared with a minimum calorie intake, from which undernourishment headcounts can be derived.

However, the above described method has been criticised for being indirect and sensitive to assumptions (Svedberg, 1999; Nubé, 2001; Klasen, 2006), not least because, headcounts and food gaps are computed at the national level only. Consequently, surveys are unable to precisely pinpoint "hunger hot spots" where policy interventions, including food aid, are most required, and to adapt these interventions to local conditions. Approaches with a more regional focus do provide more localised information, such as the Cadre Harmonisé for West Africa (CILSS, 2016), but often focus on identifying crisis situations rather than longer-term trends, and also generally focus on rural areas where food crises are perceived to be concentrated.

This paper aims to make two contributions in order to meet the need for local information on food and nutrition security, and more specifically to provide empirical evidence on nutritional status in rapidly developing urban agglomerations. First, it estimates the prevalence and total number of malnourished people (under- and over-nourished) in West African cities, using anthropometric information available for women and children in the DHS surveys at province and district level, and compare these estimates across wealth quintiles. Second, it estimates mean calorie intake in rural and urban areas, based on the recorded weights of women and children in the same surveys. In an earlier paper, Van Wesenbeeck et al. (2009) used previous DHS publications to compute and map similar anthropometric indicators for the whole of sub-Saharan Africa, but this analysis did not include geo-referenced data that is employed in this paper. Furthermore, no estimates for stunting and wasting were included at the time. Since the DHS data are geo-referenced ${ }^{4}$, the estimate of the food gap is far more explicit than the national totals presented by the FAO. The paper first describes the data and method used, before presenting and discussing the results obtained.

\section{DATA AND METHODOLOGY}

\section{Data sources}

$\mathrm{T}$ he study combines three types of data to estimate underweight, wasting and stunting for children, the Body Mass Index (BMI) for adults and caloric intakes over the total population. Firstly, it takes the population division for gender-specific age brackets from each of the 16 West African countries studied as reported by the United Nations World Population Prospects database (2017). This population pyramid is applied to all locations within the national borders as the analysis in this study did not have access to spatially detailed gender data. This specification has the limitation that population pyramids may differ substantially between locations within countries. 
Secondly, the study uses the four nutritional indicators provided by the DHS. These comprehensive, countrywide surveys are held at regular intervals in most African countries. Recent DHS survey data are georeferenced, allowing for spatially explicit data exploration. Although surveys are held in different years, given that all surveys are recent (between 2010-15), it is assumed that results can be interpreted as describing the year 2015 - the same year in which the other variables used in this study are available. Geo-referenced data are available for 12 out of 16 countries, while less detailed geo-referencing (at the provincial level) can be done for two additional countries (see Table 1). For Guinea Bissau and Mauritania, Multi Indicator Cluster Survey (MICS5), results are available for 2014 and 2015, and will be used for estimation. ${ }^{6}$

Table 1

Surveys used in the study

\begin{tabular}{|c|c|c|}
\hline Country & Survey and years used & Geo-referencing \\
\hline Benin & DHS, 2011/2012 & Yes \\
\hline Burkina Faso & DHS, 2010 & Yes \\
\hline Chad & DHS, 2014/2015 & Yes \\
\hline Côte d'Ivoire & DHS, 2011/2012 & Yes \\
\hline Gambia & DHS, 2013 & No, imputed \\
\hline Ghana & DHS, 2014 & Yes \\
\hline Guinea & DHS, 2012 & Yes \\
\hline Guinea-Bissau & MICS, 2014 & No \\
\hline Liberia & DHS, 2013 & Yes \\
\hline Mali & DHS, 2012/2013 & Yes \\
\hline Mauritania & MICS, 2014 & No \\
\hline Niger & DHS, 2012 & No, imputed \\
\hline Nigeria & DHS, 2013 & Yes \\
\hline Senegal & DHS, 2015 & Yes \\
\hline Sierra Leone & DHS, 2013 & Yes \\
\hline Togo & DHS, 2013/2014 & Yes \\
\hline
\end{tabular}

Source: DHS, https://dhsprogram.com; UNICEF/MICS, http://mics.unicef.org.

The third data source employed is the Africapolis 2018 update, produced by the Sahel and West Africa Club (SWAC; OECD/SWAC, forthcoming) Secretariat of the Organisation for Co-operation and Development (OECD). Africapolis is a geo-spatial database on cities and urbanisation dynamics in Africa ${ }^{7}$ (Moriconi-Ebrard, Harre et Heinrigs, 2016). Its methodology combines national population data, satellite and aerial imagery and other cartographic sources to provide population estimates at individual agglomeration level, 
systematic geolocation and information on the size and evolution of an agglomeration's built-up area since 1950. The Africapolis 2018 update identifies that there were over 2300 urban agglomerations in West Africa in 2015 with more than 10000 inhabitants.

\title{
Harmonising data sources
}

For population data, the first step is to aggregate the population in urban agglomerations in the Africapolis database to national level estimates. To this end, it is necessary to use other data sources. The United Nations World Population Prospects (UNWPP) database provides total population estimates, as well as disaggregated figures by gender and age. In this study, it is assumed that the total population numbers by country as listed in the UN population database remain unchanged, and rural population totals are adjusted to match the urban population from the Africapolis database.

\section{Wealth indicator}

One of the objectives of the paper is to assess the within-city inequality in food security. For this, within-city food security indicators are conditioned on the wealth index, a variable available in the DHS programme. This indicator is constructed from a large number of variables directly observed in the survey, including possession of certain items (television, radio, motorcycle, etc.), land, access to sanitation and water facilities, type of wall and roofing material on housing, cooking fuel, access to electricity and the possession of a bank account. Following a step-wise procedure, these variables are combined into a five-point scale that divides the population of each country into quintiles: "poorest", "poorer", "middle", "richer", and "richest"8. Building on Rutstein (2008), the same variables underlying the wealth index at the national level ${ }^{9}$ are used to estimate quintiles separately for urban and rural areas. The results section reports on the impact of wealth on food security status in urban areas.

\section{Estimating the nutritional status of adults and children in West Africa}

\author{
Adults (15-49 years old)
}

For adults, usually defined as those aged 15 years and above, the commonly accepted benchmark for nutritional status is the $\mathrm{BMI}^{10}$ - their weight in kilograms divided by their squared height in metres. A BMI below 16 is classified as severely underweight; 16 to 16.9 as moderately underweight; 17 to 18.4 as mildly underweight, 18.5-24.9 as normal, 25-29.9 as overweight and above 30 as obese. In the DHS, BMI values are usually only reported for adult women aged 15-49.11

\section{Children under five}

For children under the age of five, three measures are commonly used to assess nutritional status. The first - weight for height - a measure of acute food insecurity; the second - height for age - a measure of chronic food insecurity, while the third - weight for age - combines both acute and chronic effects. For all three indicators, the status is defined against an age- and sex-specific norm weight. Values that are more than three standard deviations (SD) below this norm are classified as "severely under norm"; values between two and three SD below the norm as "under norm", values between two SD below and above norm as "normal". Values between two and three SD above norm are classified as "above norm", while values above three SD above norm are considered "severely above norm". 
While for adults (15 years and above) and children under five there is broad consensus on measurements for food security, the situation for older children/adolescents is less clear. Van Wesenbeeck et al. (2009) include an extensive discussion on this topic, which led to the adoption of the following rules for the estimation of food security indicators:

1. For the 5-15 age group, there is no universally accepted method for the measurement of undernutrition. Food security indicators are often computed as the average of the indicators for children and adults reported in DHS-surveys;

2. For adults, those aged over 15, the study relies on the measurements for women from the DHS-surveys, supposing that there are no major differences in nutritional status between males and females. ${ }^{12}$

\section{Estimating calorie intake}

Following Van Wesenbeeck et al. (2009), this paper starts from the observation that a strong biophysical relation exists between the weight of a person and the calorie intake that is needed to sustain this weight. This relation is usually only invoked to determine a recommended level of calorie intake, but the estimation of actual calorie intake uses it in reverse direction: if a person has a certain weight, then this implies that the calorie intake must have sustained this weight during the period preceding the measurement, given specific allowances for physical activity (adults in general), for growth (children), and for pregnancy and lactation (women). For all age groups, and for both sexes, the relationship between weight and calorie intake is estimated and published by the FAO (FAO, 2004a), using physical activity levels and birth rates as parameters. The Annex summarises the formal relations used to compute calorie intakes and expands on the procedure followed.

\section{RESULTS}

\section{Higher prevalence of undernutrition in rural areas}

\section{Adults}

E igure 1 summarises the share of the adult population from the total sample that is - underweight (BMI < 18.5), with rural and urban subdivisions. The prevalence of adults that are underweight is higher in rural areas, 12.4\% compared to 8.6 in urban areas. However, differences in the prevalence of moderately and severely underweight individuals between rural and urban areas are minimal (less than 0.7 percentage points).

Differences across countries in total prevalence, but also in the extent to which rural/ urban differences prevail are much larger. Total prevalence of underweight is highest in Senegal, Chad and Gambia (Figure 2). It ranges from 5.9\% in Benin to 20.2\% in Senegal. Nigeria, gathering half of the region's population, ranks in the middle of the distribution with underweight prevalence standing at $8.8 \%$ and $11.5 \%$ respectively in urban and rural areas. Differences between rural and urban areas are largest in Burkina Faso and Togo. In these countries, the rural population is twice as likely to be underweight than the urban population. Differences between rural and urban areas are smallest in Liberia and Benin. Côte d'Ivoire is the only country in the sample where urban prevalence is higher than in rural areas. 
Figure 1.

Prevalence of underweight adults in West Africa $(\mathrm{BMl}<18.5)$ by location classification

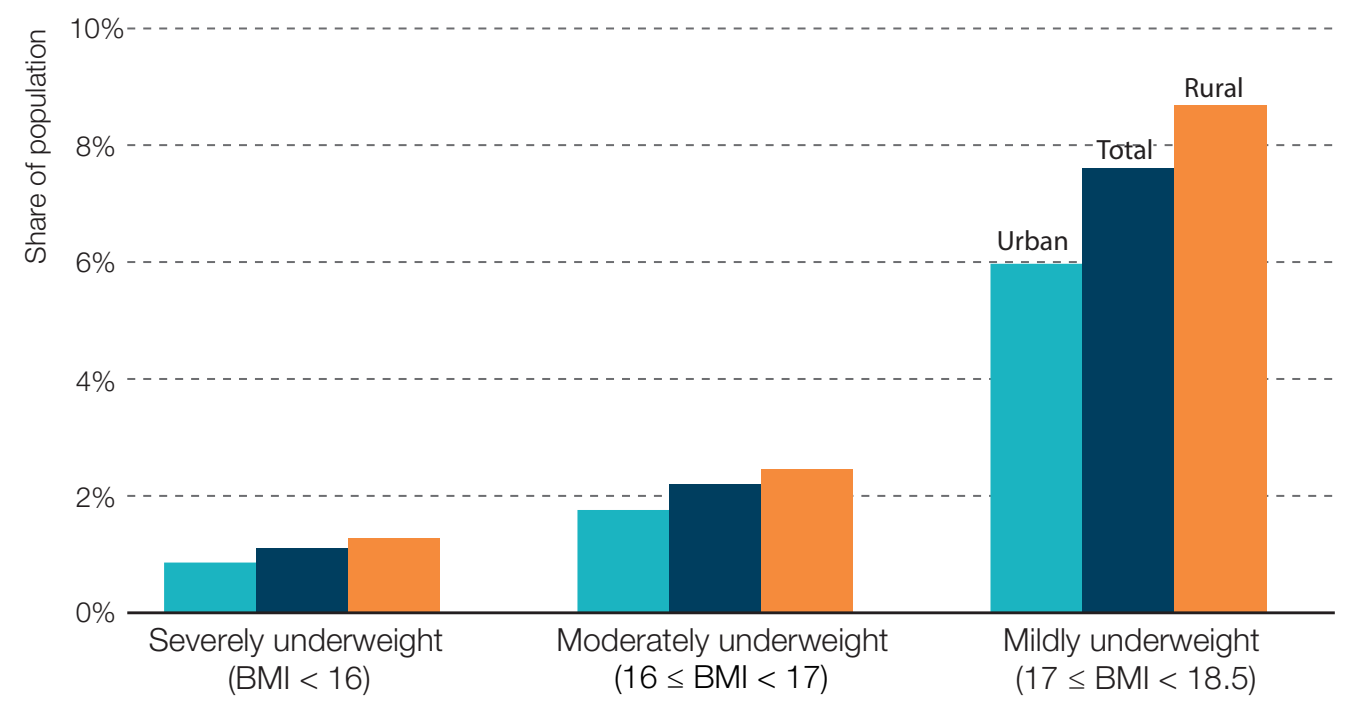

Note: Data are missing for Guinea-Bissau and Mauritania as MICS does not include adults in the survey. Source: DHS, https://dhsprogram.com; UNICEF/MICS, http://mics.unicef.org. Author's calculations based on DHS survey data.

\section{Children}

Child growth is internationally recognised as an important indicator of nutritional status and health in populations. Underweight, wasting and stunting are the three most widely used indicators for children's undernutrition ${ }^{13}$, with each variable providing specific information on the different forms of malnutrition. Wasting - or weight for height - results from an acute shortage of food or an infectious disease episode and can be reversed if the child has access to an adequate dietary intake. The percentage of children with a low height for their age - referred to as stunting - reflects the cumulative effects of undernutrition and infections. This measure can therefore be interpreted as an indication of long-term restrictions on a child's growth potential. Underweight - or weight for age - is a composite indicator and can reflect both short- and long-term instances of children's malnutrition.

\section{Children: Weight for age (underweight)}

The estimated prevalence of underweight children as a percentage of the overall child population is averaged across 16 countries. It shows that in rural areas, $10.2 \%$ of children are severely underweight, as compared to $6.4 \%$ in urban areas, while $22.9 \%$ are moderately underweight in rural areas, against 16.6\% in urban areas (Figure 3). Overall, 8.5\% of children in the study area are severely underweight, with another $20 \%$ being moderately underweight. Again, there are substantial differences in the total prevalence of underweight children, as well as for the difference between rural and urban areas. Over two-fifths of children in Niger and one-third of all Nigerian and Chadian children are classified as underweight, while in Ghana around one-eighth are underweight. 
Figure 2.

Prevalence of underweight adults $(\mathrm{BMl}<18.5)$ by country and location

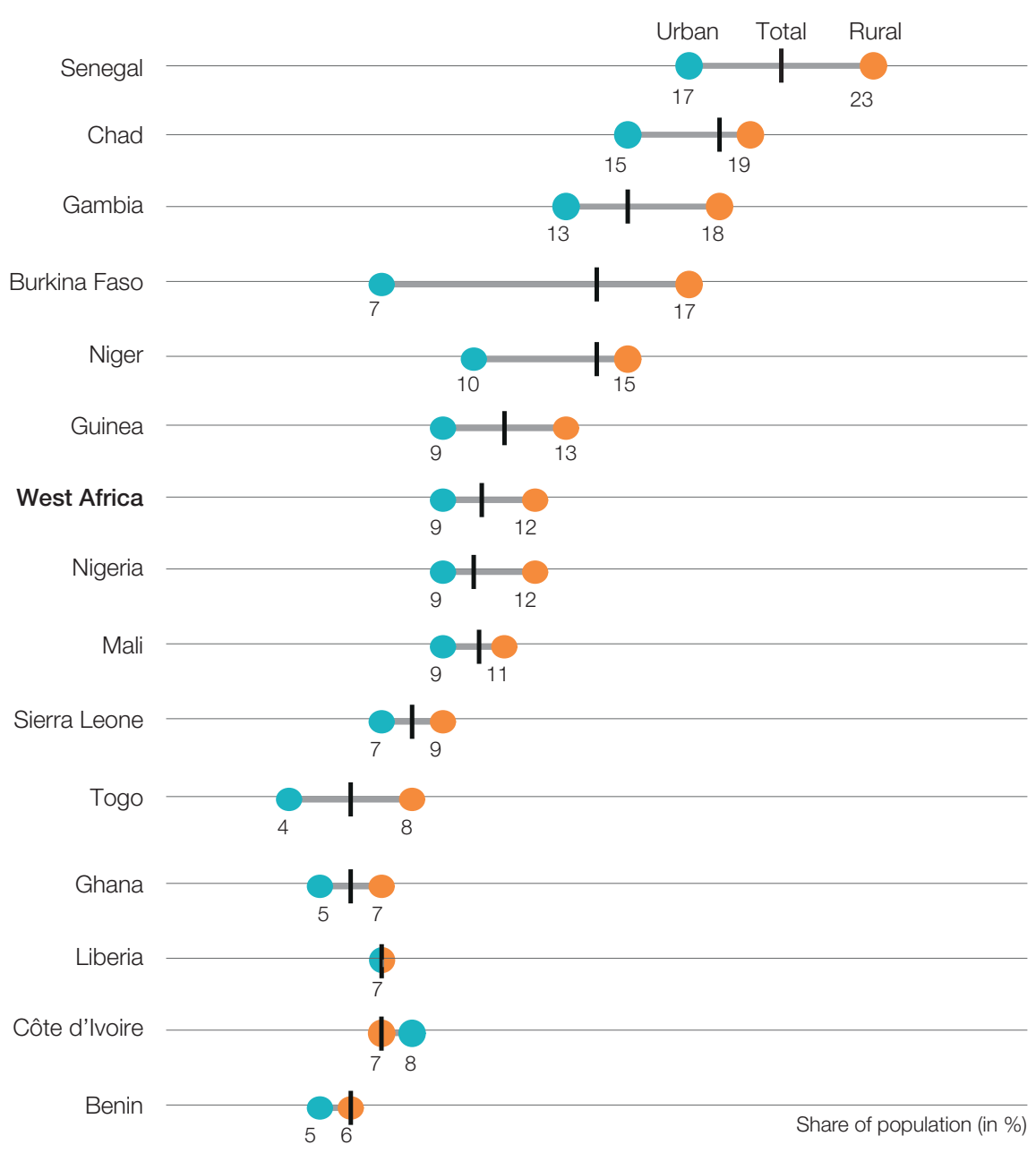

Note: Data are missing for Guinea-Bissau and Mauritania as MICS does not include adults in the survey. Source: DHS, https://dhsprogram.com; UNICEF/MICS, http://mics.unicef.org. Author's calculations based on DHS survey data.

\section{Children: Weight for height (wasting)}

Acute food insecurity in the West African region shows a somewhat less alarming picture than that for underweight children ${ }^{14}$. Overall, $3.5 \%$ of children are classified as severely wasted, and $9.9 \%$ are moderately wasted. However, prevalence rates in rural and urban areas are more similar. In rural areas, 3.4\% of children are severely wasted and $10.2 \%$ are moderately wasted, compared to $3.6 \%$ and $9.5 \%$ respectively in urban areas (Figure 4 ). The country specific results again show large differences across countries, although the spread is lower than for underweight children. As with those underweight, Mauritanian children living in urban areas are significantly more likely to suffer from wasting than those in rural areas (21\% compared to 15\%). Sierra Leone and Togo also have greater wasting in urban areas, but at a much lower scale: $7 \%$ versus $6 \%$ and $9 \%$ versus $8 \%$, respectively. 
Figure 3.

Prevalence of underweight children by country and location

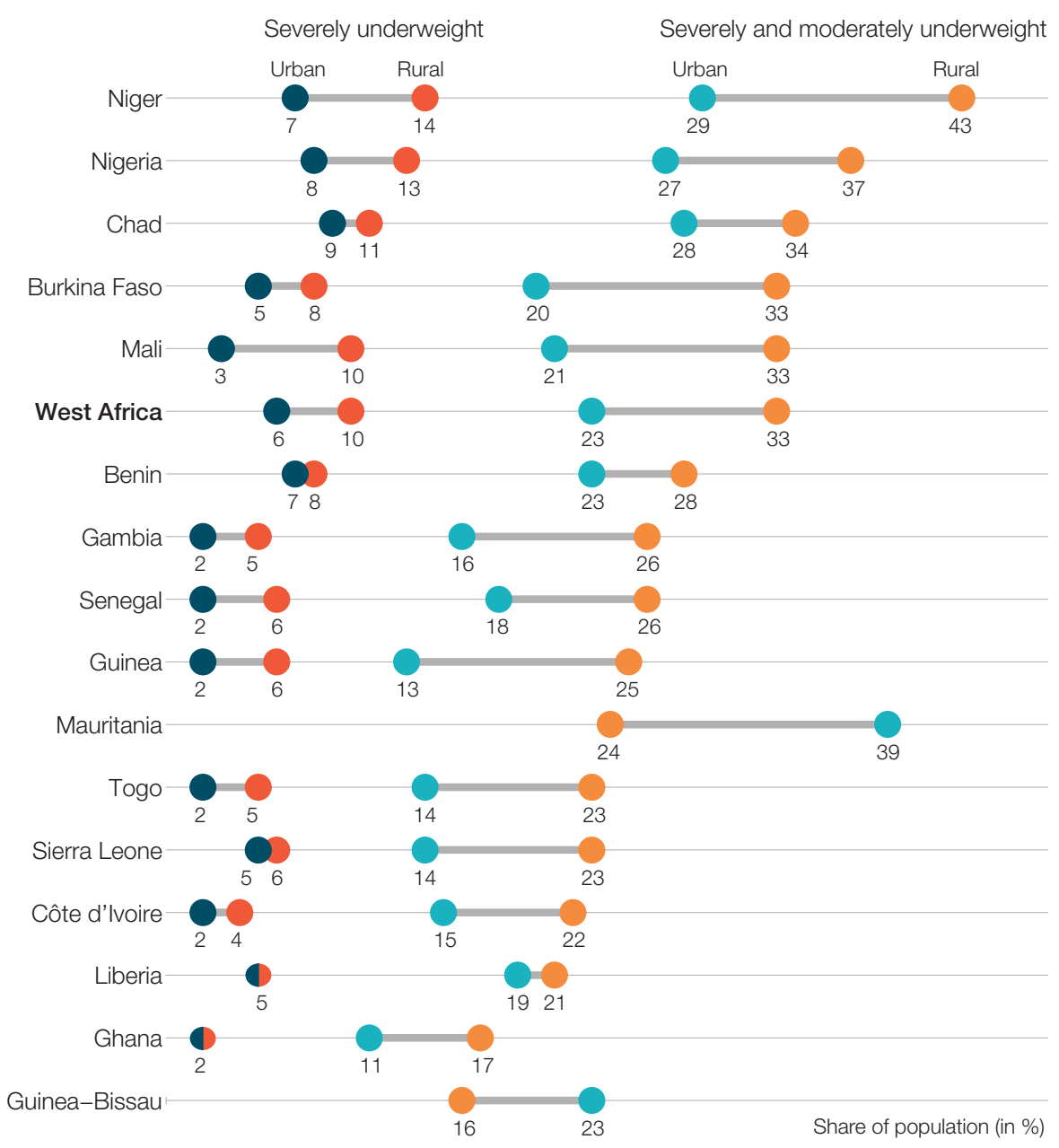

Source: DHS, https://dhsprogram.com; UNICEF/MICS, http://mics.unicef.org. Author's calculations based on DHS survey data,

\section{Children: Height for age (stunting)}

Levels of stunting across West Africa indicate that chronic food security is a serious cause for concern: $13.7 \%$ of children in the study area are severely stunted and an additional $9.9 \%$ are shown to be moderately stunted. In rural areas $17.5 \%$ of children are severely stunted with another $17.6 \%$ moderately stunted, while the numbers for urban children are notably lower at $9.2 \%$ and $11.4 \%$, respectively (Figure 5). As with the previous indicators, the spread across countries is large. Similar to the trends observed for wasting and overweight children, Ghana has the lowest prevalence of stunting in West Africa and Mauritania one of the highest, while Mauritania and Guinea-Bissau again stand out as the only two countries to have a higher prevalence of stunting in urban areas. Perhaps more surprisingly, Benin has the highest level of stunting across West Africa despite having a lower prevalence of underweight children than the regional average, and Gambia one of the lowest even though it has mid-range scores for underweight and wasted children. 
Figure 4.

Prevalence of wasted children by country and location

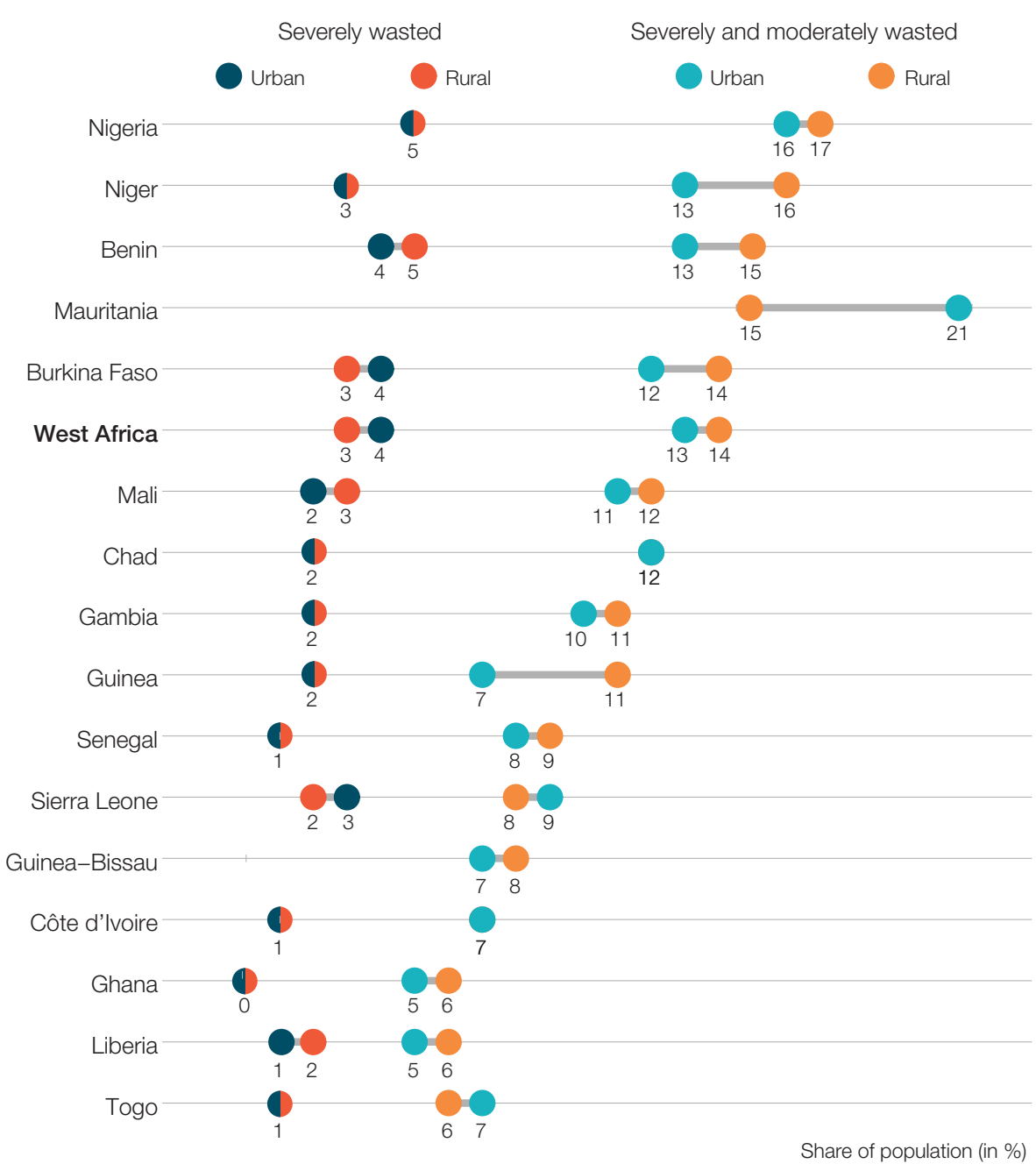

Source: DHS, https://dhsprogram.com; UNICEF/MICS, http://mics.unicef.org. Author's calculations based on DHS survey data.

Total population: BMl and weight for age/BMl and weight for height

To obtain a population-wide image of the prevalence of undernutrition, indicators for children and adults are combined and weighted considering their respective shares in the population. The most common combination is that of BMI measures for adults and underweight measures for children (weight for age) ${ }^{15}$. An alternative measure would be to consider the short-term nutritional indicator for children (wasting) instead of underweight, which as a height-controlled indicator can be argued to be more closely related to BMI. Using the data for wasting, instead of the underweight population, and following the same method, total percentages are computed for rural and urban areas, as well as for the total populations (Figure 6).The percentages computed using weight for height (wasting) are $70-75 \%$ of those computed using weight for age (underweight), which reflects that each indicator provides a different perspective on the acuteness and chronicity of food security issues. Correlation coefficients between the two indicators range from 0.90 for urban populations to 0.94 for rural populations, equalising out at 0.92 , overall. Thus, the general picture of undernutrition in West Africa does not change substantially between urban and rural areas depending on which indicators is used. 
Figure 5

Prevalence of stunted children by country and location

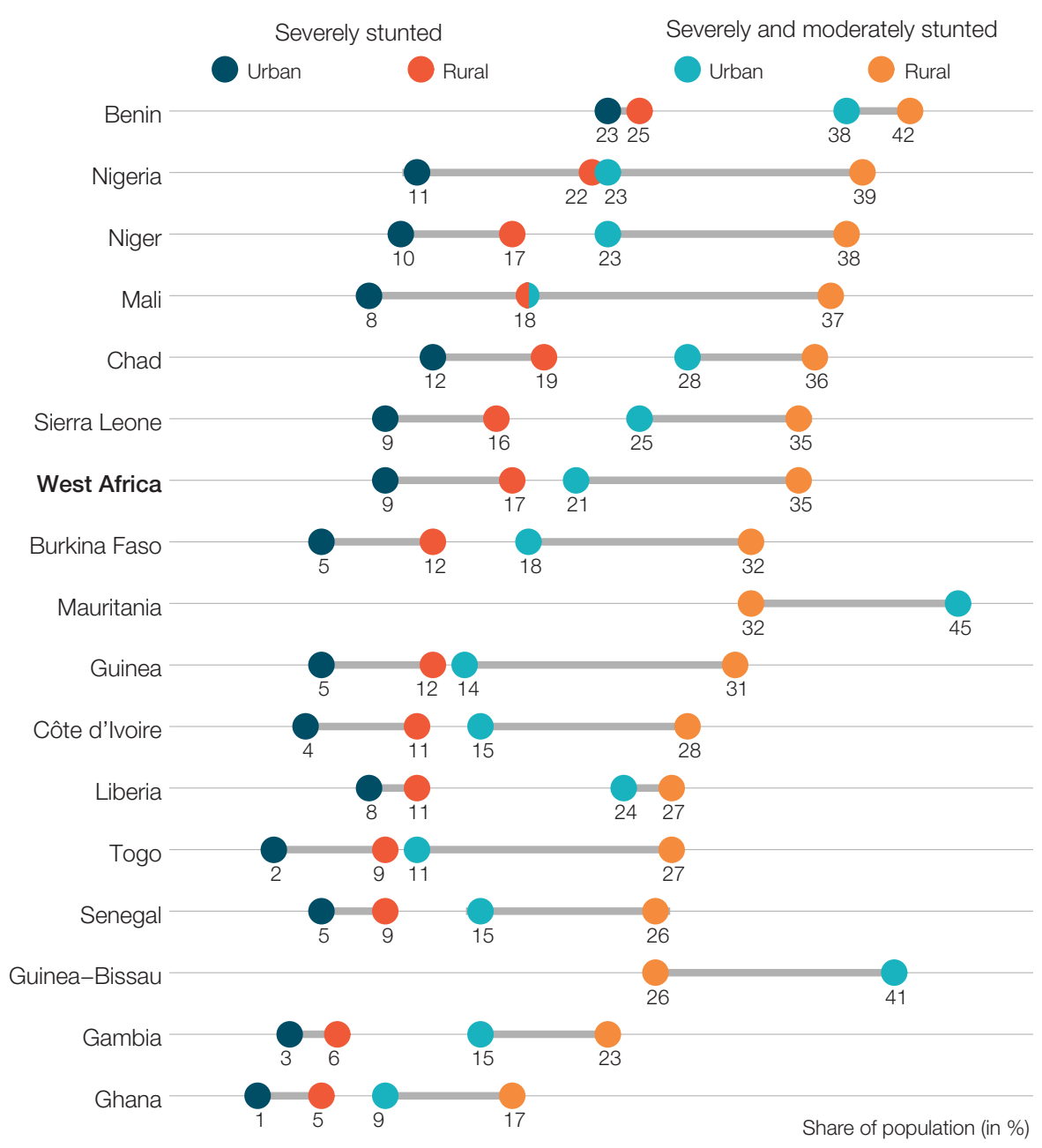

Source: DHS, https://dhsprogram.com; UNICEF/MICS, http://mics.unicef.org. Author's calculations based on DHS survey data.

The prevalence of undernutrition is higher in rural than urban areas across all West African countries for both adults and children. Two countries in the Sahel region, Chad and Niger, show the highest prevalence of undernutrition, while three coastal countries Ghana, Togo and Côte d'Ivoire - have the lowest total undernutrition prevalence. However, the regional prevalence of undernutrition in urban areas remains high and is a worrying issue. It ranges from 10\% to 13\%, depending on the indicator selected for underweight children, and is relatively similar to prevalences in rural areas (13\% to 18\%). The high level of undernutrition in urban areas in Nigeria deserves special attention given the size and share of its population living in cities: 54\% of the total live in urban agglomerations (OECD/SWAC, forthcoming).

Child undernutrition rates in urban areas were as high as $19.3 \%$ in Chad, only a few percentage points below the average proportion of underweight children in rural areas (23.8\%). The total number of underweight children in West African cities is estimated at almost 6.3 million, while almost 3.4 million children experience wasting. 
Figure 6.

Prevalence of undernutrition by country and location

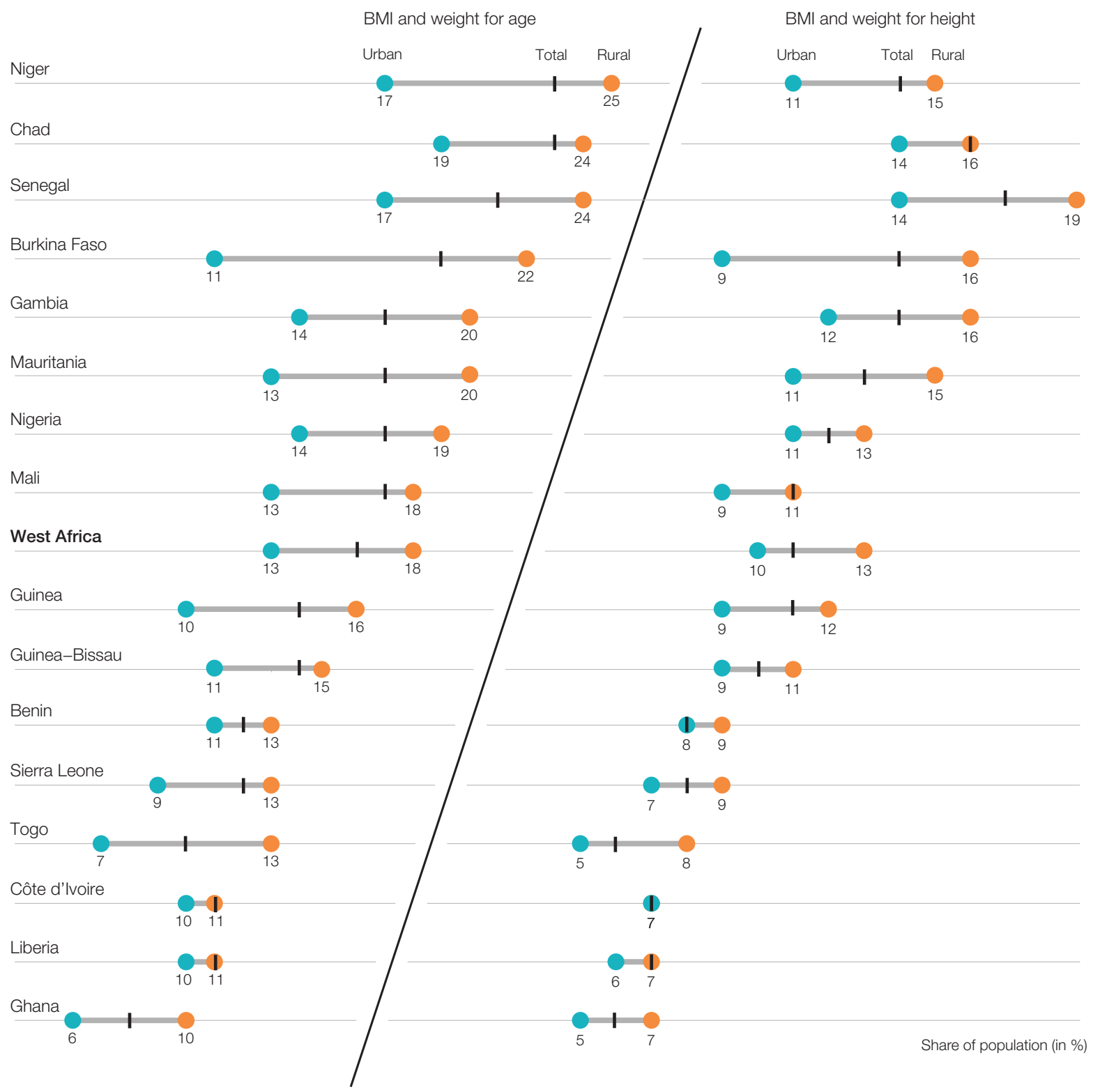

Source: Since DHS data for Guinea-Bissau and Mauritania do not include adults, regional averages are used for BMI estimates in these two countries. Source : EDS, https://dhsprogram.com/; UNICEF/MICS, http://mics.unicef.org/. Calculs des auteurs à partir des données EDS.

\section{Millions of urban dwellers face food insecurity}

When the underweight variable is applied for children (Figure 7), the total number of underweight individuals in West Africa is 58.4 million, whereas when figures for wasting are used, this number decreases to 41.7 million. 22 and 16.9 million of them, respectively, are living in cities. This decline is due mainly to the significantly lower estimates for wasting prevalence in Nigeria: 8.4 million less Nigerian children are classified as suffering from wasting relative to those who are classified as underweight.

Nigeria represents $65 \%$ of the region's total underweight urban population, given its much large urban population relative to other West African countries. However, the prevalence of underweight individuals in urban areas in Niger and Chad is significantly larger than their small urban populations might suggest. 
Figure 7

Total population affected by undernutrition (in millions)

BMI and weight for age, number of people undernourished (in millions)

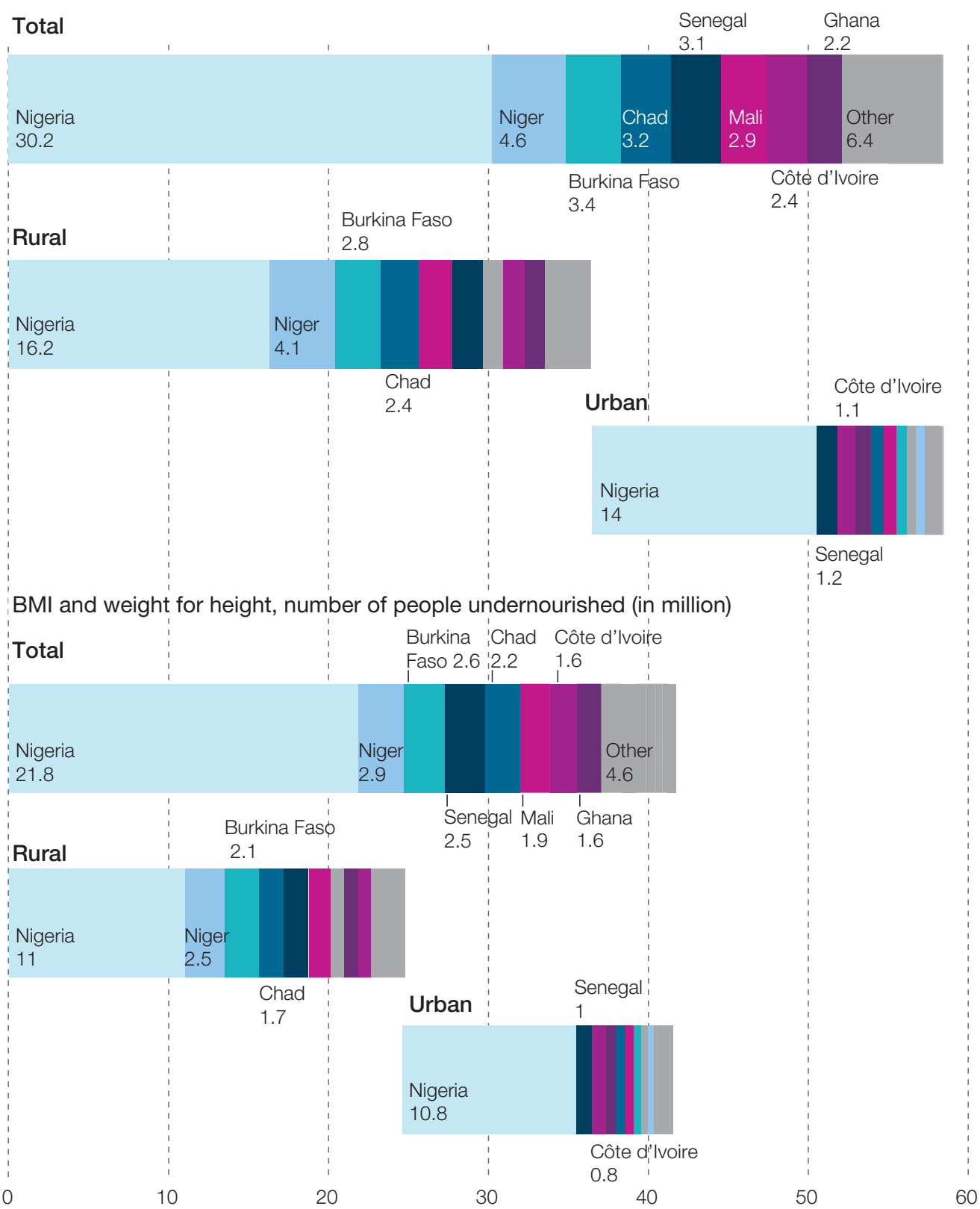

Source: Author's calculations based on DHS survey data, https://dhsprogram.com.

\section{Over-nutrition is quickly becoming an important issue in urban areas}

Over-nutrition, i.e. those overweight and obese, is rapidly becoming a problem as important as undernutrition in certain West African countries. The problem of the "double burden" of under- and over-nutrition poses severe challenges to countries' health systems, which are generally already overstretched in the region. In West Africa, the prevalence of overweight and obese adults is $17.6 \%$ and $7.6 \%$, respectively, and $1.7 \%$ and $0.75 \%$ for children ${ }^{16}$ (Figure 8). 
Figure 8.

Prevalence of overweight and obese adults

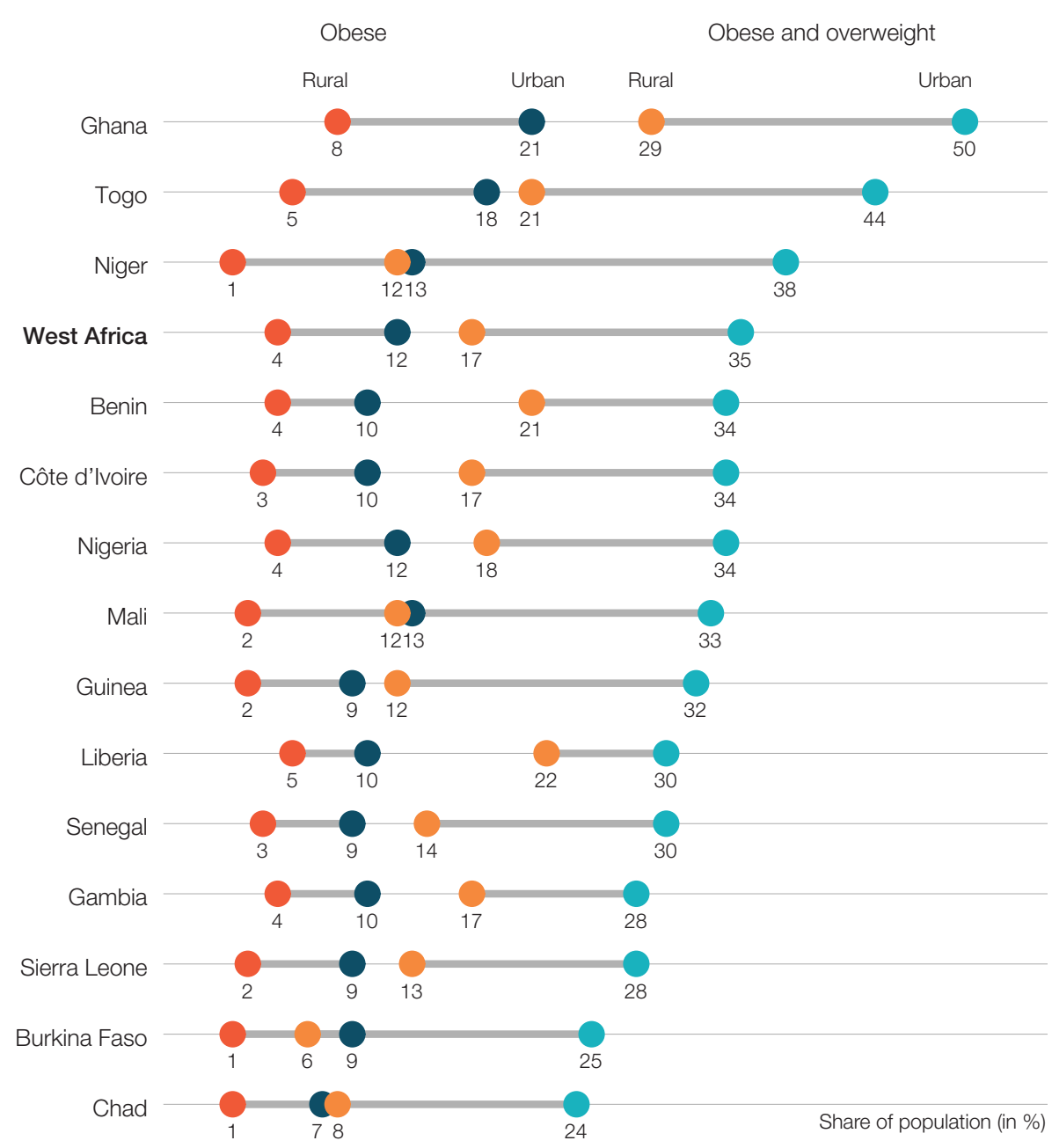

Note: Data are missing for Guinea-Bissau and Mauritania as MICS does not include adults. In this figure, West Africa is representative of the whole region, excluding the two aforementioned countries and Cabo Verde. Source: Author's calculations based on MICS survey data, http://mics.unicef.org.

\section{Adults}

For all countries, the prevalence of overweight and obese adults is higher in urban than in rural areas. These rates are alarmingly high in many countries including those that also have high percentages of underweight adults, such as Niger (14\%underweight and 17\% overweight or obese). In total, 25\% of the West African adult population is overweight or obese (versus 11\% who are underweight). The prevalence of overweight individuals is particularly high in Ghana, while it is the lowest in Chad. These results reflect the rapid shifts in diet and activity that take place as countries (and households) become more prosperous.

The wealthiest/wealthier West African countries are undergoing a nutritional transition, accompanied by decreased physical activity and an increased number of overweight and obese individuals. The spread in over-nutrition is particularly high between urban and rural areas, highlighting the change in food consumption habits (and activity levels) as individuals move to cities. In Niger, for example, obesity prevalence is $13 \%$ in urban areas and 1\% in rural areas (Figure 8). Countries with less relative differences in obesity prevalence between urban and rural areas, such as Liberia, Benin and Ghana, have higher rural prevalence rather than lower urban obesity prevalence. 
The proportion of children and teenagers who are either overweight or obese is much less severe than for adults. In percentage terms, as well as in absolute numbers, the problem is much less pronounced than for underweight, stunting and wasting. On average, the percentage of children who are overweight or obese is $2.5 \%$, measured by the weight-toheight ratio. For the West African region as a whole, the estimated number of overweight children is around 1 million, while there are an estimated 0.5 million obese children, spread roughly evenly between urban and rural areas, potentially indicating that obesity issues for young West Africans is not specific to location. This contrasts with adult overnutrition, which is a greater issue in urban than rural areas.

\section{The urban poor face similar levels of food insecurity as rural dwellers}

Analysing within-city diversity of food insecurity, in particular the distribution of undernutrition and overnutrition by wealth quintile, provides a number of interesting insights. The percentage of the population that is underweight decreases with rising income, with lower rates of underweight individuals in richer wealth groups. Undernutrition in urban areas is of particular concern for the poor and poorest households, which are as likely, if not more likely, as rural households to be underweight (both adults and children) and suffering from wasting and stunting. Whereas levels of overweight and obese individuals are specifically high in urban areas, in particular for better-off households. Approximately $42 \%$ of the richest urban wealth group is either overweight or obese; over-nourishment only concerns $15 \%$ of rural dwellers across West Africa.

\section{Adults}

Overall, the relation between BMI and wealth in urban areas is in line with expectations (Figure 9). For low values of BMI, the poorest and poor quintiles are overrepresented, while for high values, the richer and richest quintiles dominate. Comparing the incidence of underweight individuals in urban and rural areas, the percentage of the poor and poorest urban dwellers that are underweight is comparable with that of rural areas: the prevalence of those who are severely and moderately underweight in the poorest quintile in urban areas reaches $1.3 \%$ and $2.3 \%$, respectively, comparing to $1.3 \%$ and $2.5 \%$ on average in rural areas. These results suggest that earnings of the poorer urban households are not sufficient to pay for the relatively higher cost of food in cities. Indeed, poor urban households in West Africa spend USD 347 per capita per year on food compared to USD 297 per capita per year for poor rural households (Allen, 2017). Thus, poor urban households don't necessarily consume more food than their poor rural counterparts, they just pay more per unit of consumption.

As in urban areas, the prevalence of underweight individuals in rural areas follows a clear pattern with wealth quintiles: the share of adults with a low BMI is higher in lower wealth quintiles, while the reverse is true for adults with a high BMI (Figure 10). Similarly, at the opposite end of the wealth spectrum, problems of individuals being overweight or obese are concerns for the richest rural households. However, the variance from the underweight and overweight averages is smaller between wealth quintiles among rural households than among urban households, indicating greater food consumption inequalities in cities.

These results highlight the significant differences in malnourishment dynamics between rural and urban areas. A particular example, and concern, is prevalence of obesity among wealthier urban households. In the medium-term, this could pose some serious public health issues as the region continues to urbanise. 
Figure 9.

BMI by wealth quintile in urban areas and rural average (in \% of total population)

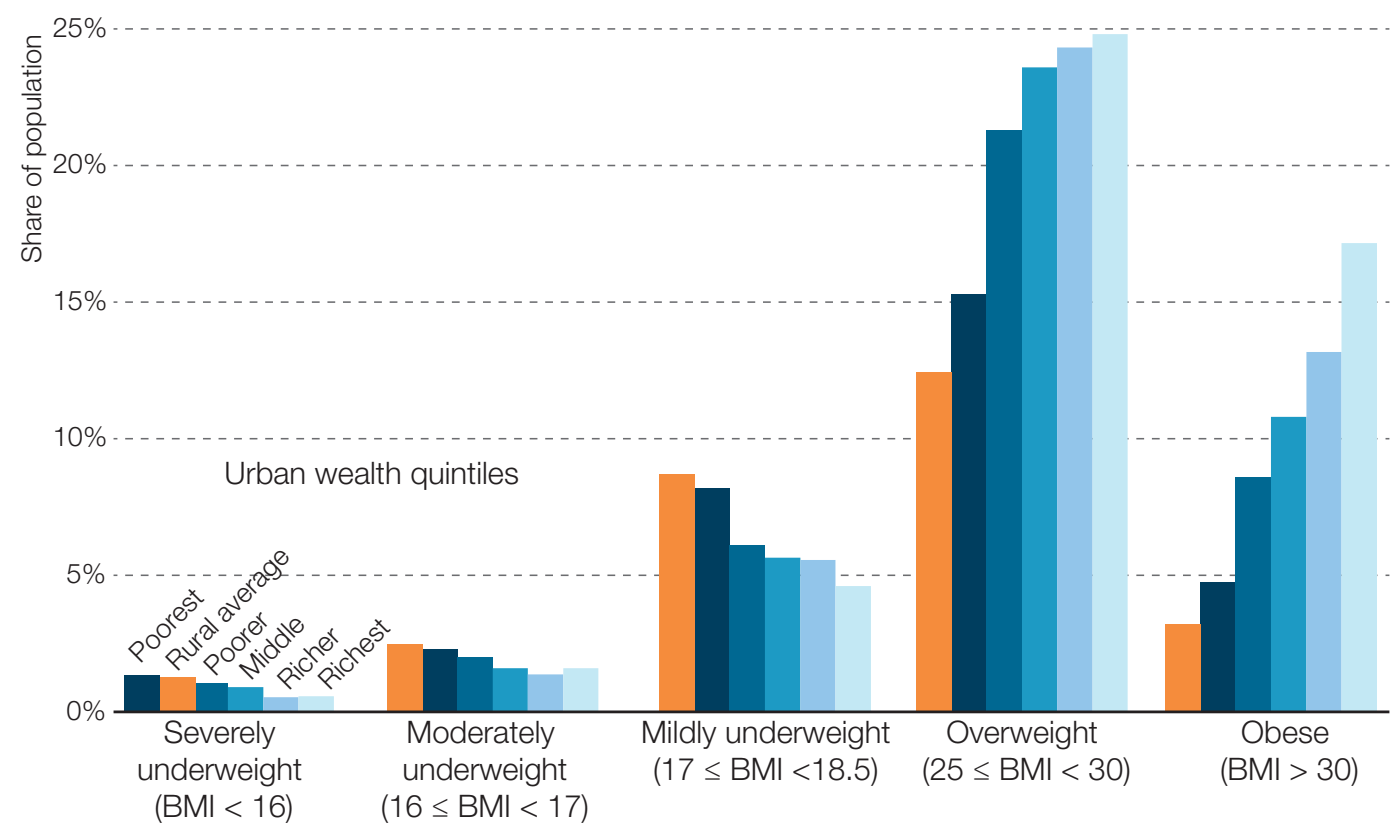

Source: Author's calculations based on DHS survey data, https://dhsprogram.com.

Figure 10.

BMl by wealth quintile and location

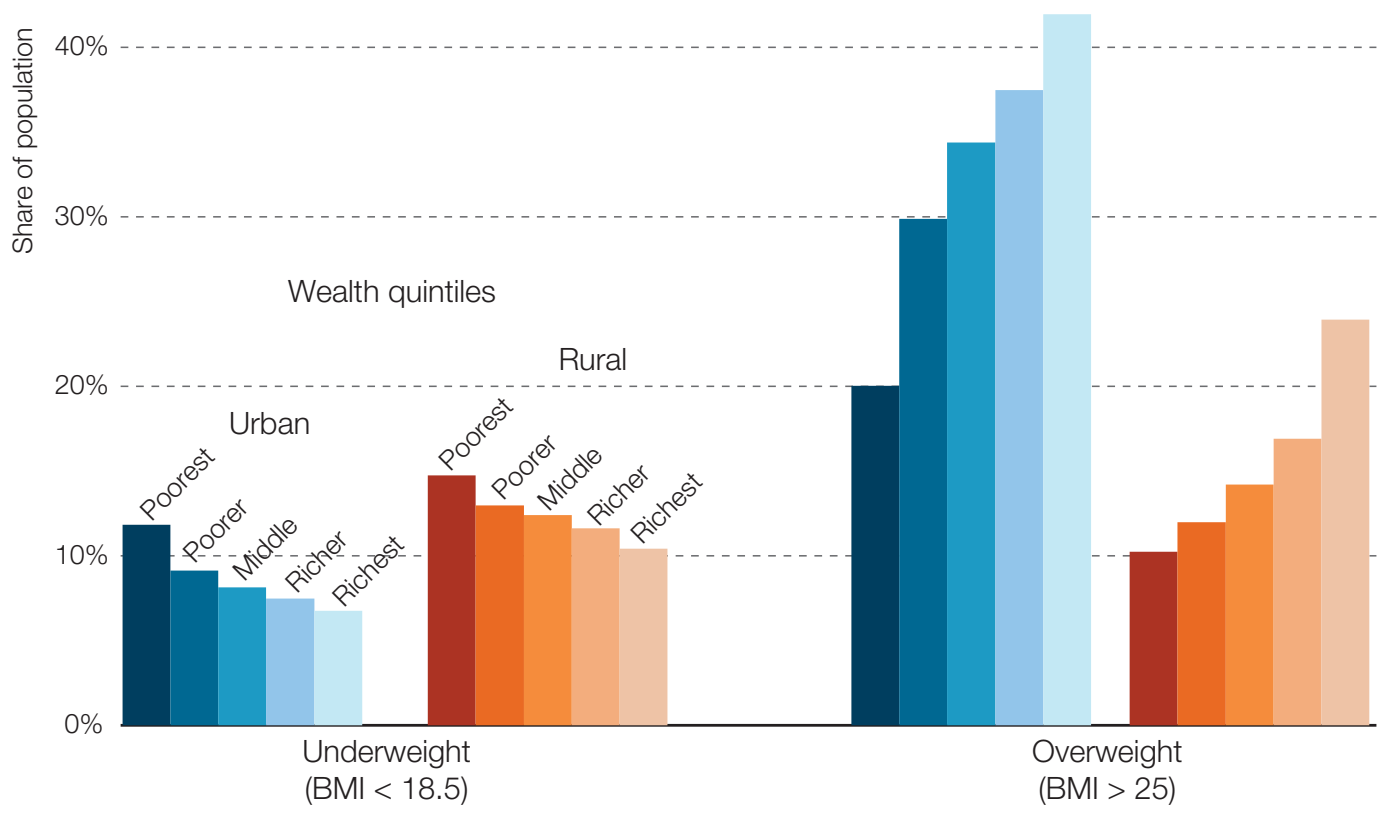

Source: Author's calculations based on DHS survey data, https://dhsprogram.com.

Children: Weight for age, weight for height, height for age

In general, the situation for children follows that for adults, including when within-city diversity is incorporated in the analysis, although the problem of overweight/obesity is much less pronounced. For the underweight (weight for age), severe conditions are much 
more prominent in lower wealth classes, affecting $8.4 \%$ of the poorest quintile compared to $3.1 \%$ among the richest (Figure 11). Yet, prevalence of severe and moderate underweight conditions in the poor and poorest quintiles is lower than in rural areas (9.6\%). Mildly underweight conditions are similar across wealth quintiles and between rural and urban areas.

Figure 11.

Underweight children by wealth quintiles in urban areas and rural average

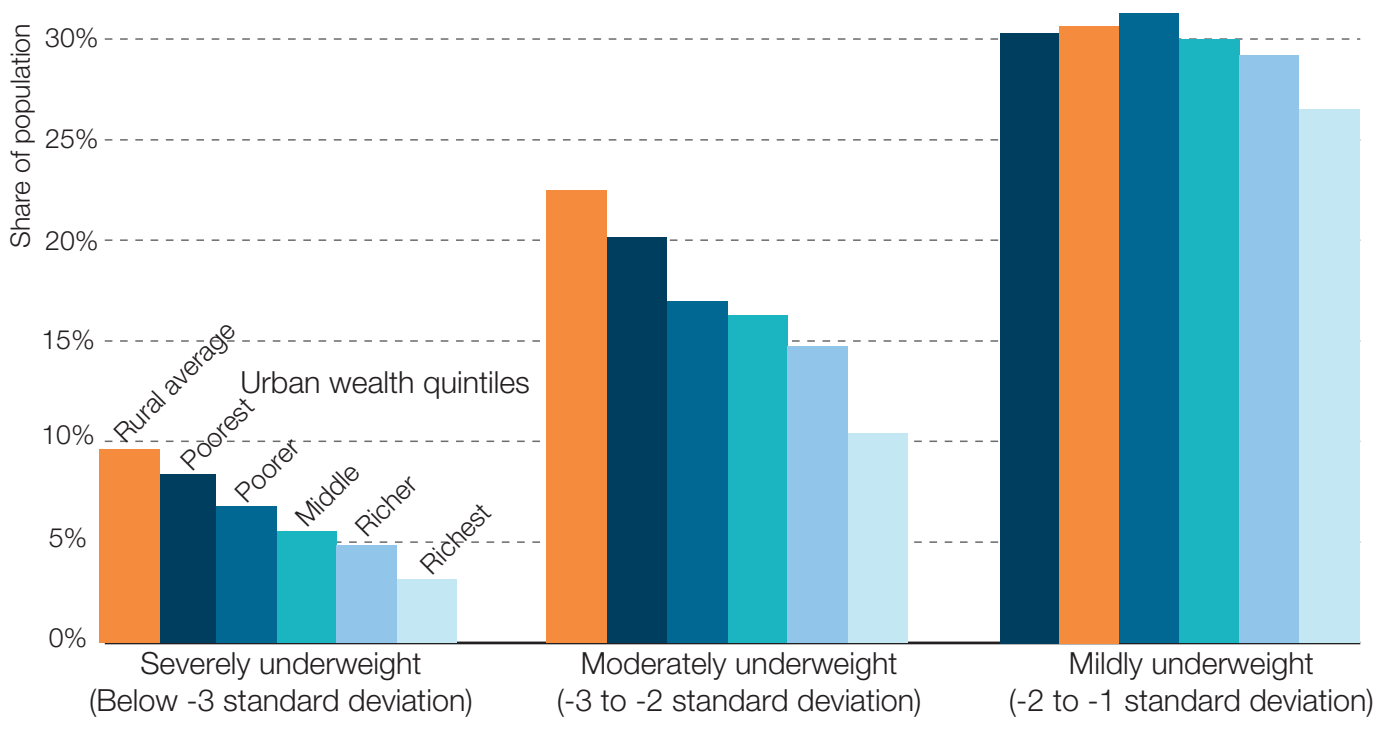

Source: Author's calculations based on DHS survey data, https://dhsprogram.com.

For stunting - an indicator of chronic food insecurity for children - results differ slightly from that for acute food insecurity (Figure 12). A clearer relation between severe stunting and wealth quintiles can be observed, with children in poorer households being twoto three-times more likely to suffer from stunting than children in richer households. Comparisons between rural and urban sub-areas reveals that stunting rates in poor urban areas are considerably higher than those in rural areas for severe stunting, but this regional difference becomes increasingly less pronounced for moderate and mild stunting.

The relation between wasting - the short-term indicator of child nutritional status - and wealth quintiles in urban areas is not as strong as with the aforementioned two indicators (Figure 13), and fewer children are classified as severely and moderately wasted. Overall, rural and urban areas do not have substantially different levels of wasting. As a measure of acute food insecurity, averages of wasting estimates across the region level off some country-specific and localised hotspots. This suggests that over the selected survey years, acute food insecurity was not specific to urban or rural contexts.

The combination of results for adults and children across these indicators confirms the importance of undernutrition for the poor and poorest urban households in West Africa, a group that represents $40 \%$ of the region's total urban population. Adding the rising overweight and obesity issues that are affecting approximately $35 \%$ of the adult population living in cities and towns, there are almost 40 million people living in the region's urban areas who are not receiving the correct nutrition for their needs. 
Figure 12.

Stunting by wealth quintiles in urban area and rural average

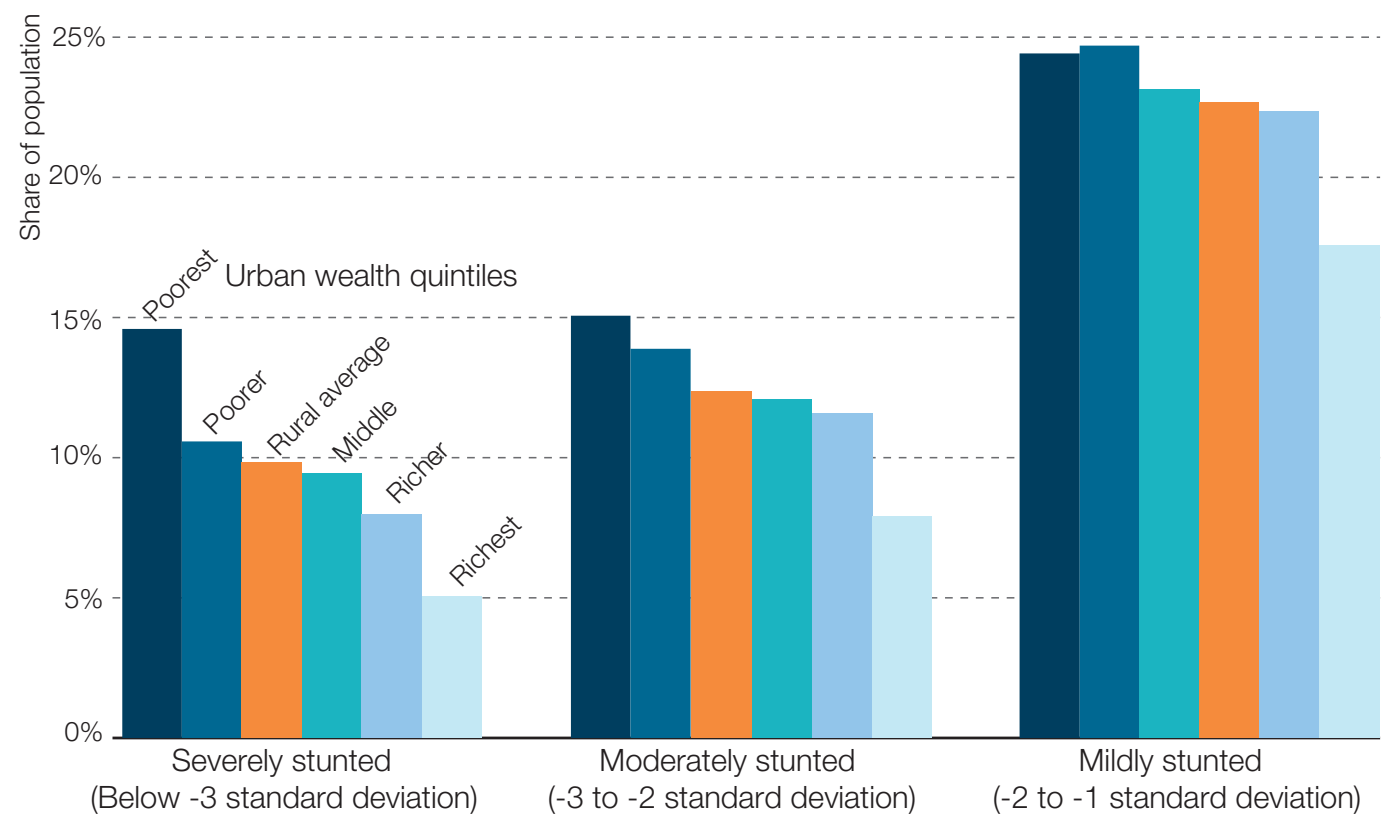

Source: Author's calculations based on DHS survey data, https://dhsprogram.com.

\section{Estimating urban and rural calorie intakes}

Following the methodology explained in the previous section, it is now possible to compute calorie intakes separately for urban and rural areas for the first time. This is a significant step forward compared to the FAO's Food Balance Sheet estimates, which are only available at country level.

Figure 13.

Wasting by wealth quintiles in urban areas and rural average

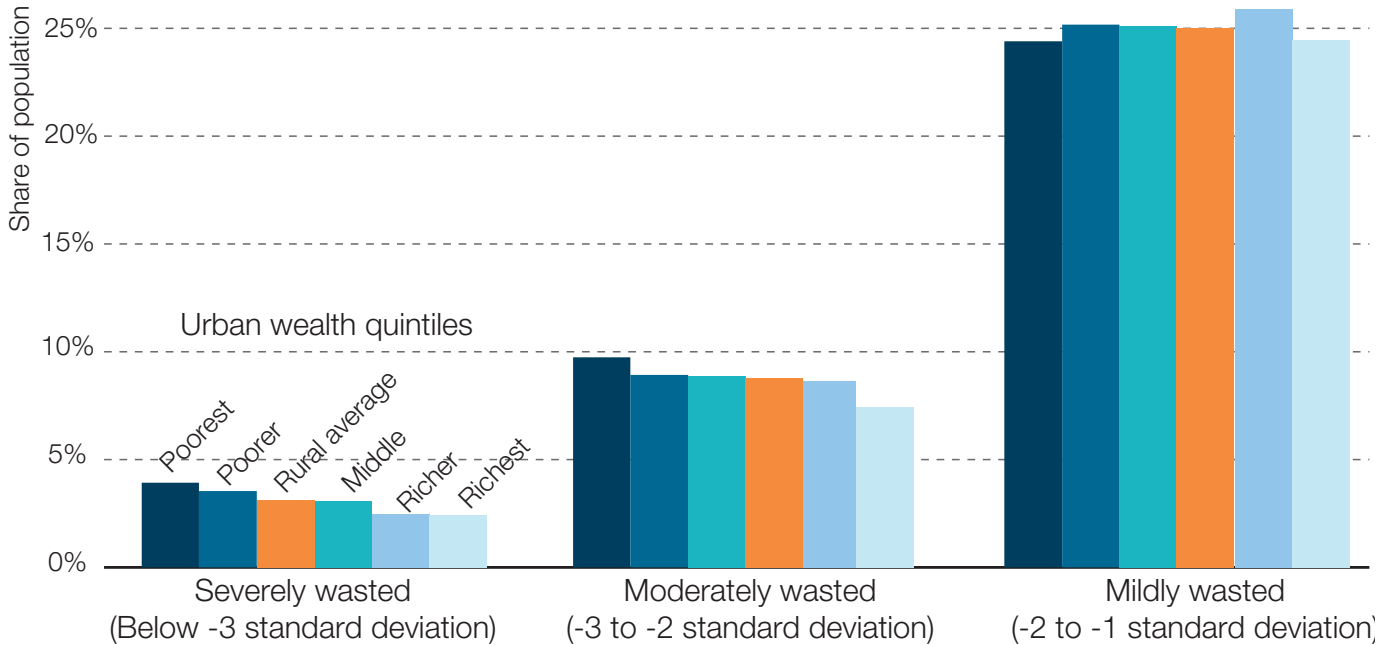

Source: Author's calculations based on DHS survey data, , https://dhsprogram.com. 
The results clearly show that calorie intakes in urban areas are higher than in rural areas for all countries (Figure 14). Sierra Leone is the only country where intakes are almost equivalent in the two locations. The highest intakes are reported for urban Ghanaians $(2602 \mathrm{kcal}$ per day, per capita), which also reflects the relatively high prevalence of overweight and obesity in the country. In rural Burkina Faso, calorie intakes are the lowest throughout the region, with an average of $2311 \mathrm{kcal}$ per day, per person. If urban and rural-specific parameters were readily available to compute the distribution of dietary energy consumption (DEC), it would be possible to estimate the prevalence of undernourishment separately by location. The differences in DEC between locations range from $2 \%$ to $6 \%$, suggesting that the calorie gap between urban and rural populations might not be widely different.

The above results highlight potential sources of bias when using average calorie intakes to compute the prevalence of undernourishment in countries. By averaging the lack and excess of calorie intakes by individuals, the overweight population is counterbalancing those who are underweight in the FAO's estimations of the prevalence of undernourishment. It might results in an underestimation of the number of individuals who are underweight, whilst simultaneously incorrectly assessing the extent of overweight and obesity issues.

Figure 14.

Estimated calorie availability in Kcal per person, per day

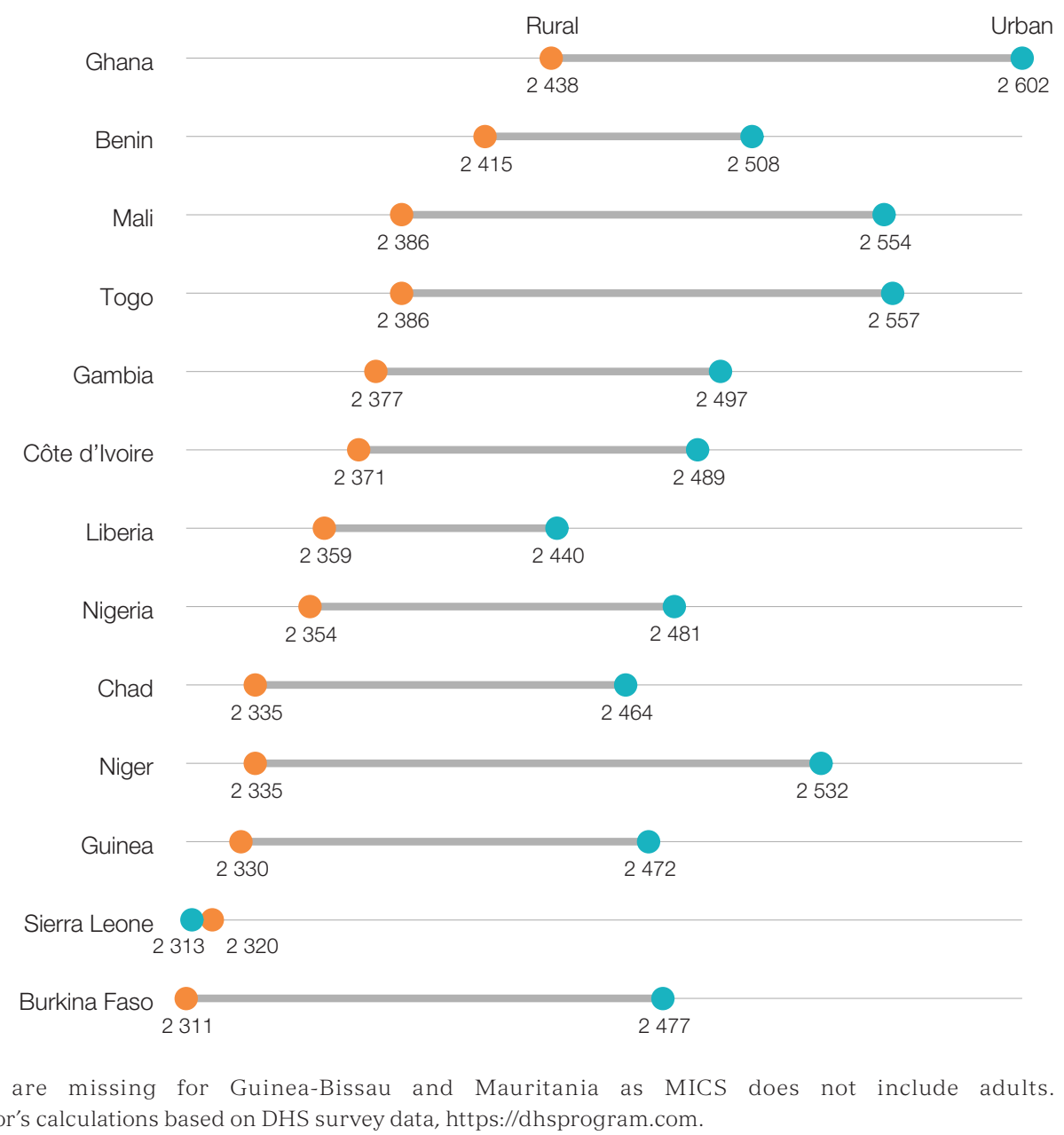

Source: Author's calculations based on DHS survey data, https://dhsprogram.com. 


\section{CONCLUDING REMARKS}

$\mathrm{T}$ his study has shown that the food security situation in West Africa differs substantially between countries and between rural and urban areas. Using various indicators for adult and child food security and nutrition, the paper confirms the general notion that the prevalence of undernutrition, as well as its absolute numbers are higher in rural areas than in urban areas. Yet, in some countries, differences in food insecurity prevalence between urban and rural areas are very narrow. Indeed, the two poorest quintiles living in towns and cities show undernutrition prevalence for most indicators that are above rural averages. In urban areas, overweight and obesity issues are almost as significant as for undernutrition, highlighting the increasing challenge from the "double burden of malnutrition" that these city areas face. These findings call for greater research efforts to identify more appropriate metrics to monitor food and nutrition security in urban areas.

\section{NOTES}

[1] See https://dhsprogram.com/.

[2] See, for example, the global database on child growth and malnutrition at: www.who.int/ nutgrowthdb/en/.

[3] FAO Food Balance Sheets take also into account feed, seed, stocks, exports to derive food supply/ availability.

[4] See the data section for an elaboration of geospatial specificity of the data used.

[5] See http://mics.unicef.org/.

[6] For Cabo Verde, the latest MICS results available are for 1994 and did not include a rural-urban distinction. Given the little relevance of this data for the current analysis it is not included here.

[7] The Africapolis data (2015 update) is available at stats.oecd.org, in the demography and population section.

[8] For details on this approach, see: https://www.dhsprogram.com/topics/wealth-index/WealthIndex-Construction.cfm, and https://www.dhsprogram.com/programming/wealth\%20index/ Steps_to_constructing_the_new_DHS_Wealth_Index.pdf.

[9] DHS datasets include a continuous variable, which is used to compute quintiles at the national level.

[10] BMI is weight (in kilograms) divided by the square of the height (in metres).

[11] Following Miller (2003), BMI is truncated to a minimum value of 14 and a maximum value of 48.

[12] There is little empirical evidence to support an alternative assumption. It is also impossible to know if this assumption would lead to an over- or underestimation of the nutritional status of the total adult population. This is clearly an issue for further research.

[13] The standards set by the WHO for these indicators are as follows. Underweight: weight for age < -2 SD of the WHO Child Growth Standards (CGS) median. Stunting: height for age $<-2$ SD of the WHO CGS median. Wasting: weight for height $<-2$ SD of the WHO CGS the WHO CGS median. Overweight: weight for height $>+2$ SD of the WHO CGS median.

[14] As an indicator of acute food insecurity, results for wasting can vary significantly over time. The DHS surveys used in this paper have been conducted over several years, from 2010 to 2015, and regional averages smooth out the effects of the food crises that may have occurred in some countries over the period.

[15] Calculations for missing data are explained in the section on data and methods. In addition, as MICS data only covers children, missing data for Mauritania and Guinea Bissau is imputed using ratios between total and rural/urban underweight percentages and ratios between percentages of underweight adults and children for the whole sample.

[16] For children, the commonly used indicator weight for height is used. 


\section{REFERENCES}

Allen, T. (2017), "The cost of high food prices in West Africa", West African Papers, No. 8. OECD Publishing, Paris, http://dx.doi.org/10.1787/c2db143f-en.

CILSS (2016), Identification and Analysis of Areas at Risk and Populations Affected by Food and Nutrition Insecurity in the Sahel and West Africa - Manual, Permanent Interstate Committee for Drought Control in the Sahel, Ouagadougou, http://fscluster.org/sites/default/files/documents/ch_manual_ en_003.pdf.

FAO (2017), Food security indicators, Food and Agriculture Organization, Rome, http://www.fao.org.

FAO (2004a), Calculating Population Energy Requirements and Food Needs, Software developed in conjunction with "Human Energy Requirements", Food and Nutrition Technical Report Series No. 1, Food and Agriculture Organization, Rome, www.fao.org.

FAO (2004b), “Human Energy Requirements: Report of a joint FAO/WHO/UNU expert consultation”, FAO Food and Nutrition Technical Report Series No. 1, Food and Agriculture Organization, Rome, www.fao.org.

Jones, T.W. (2004), “Using Contemporary Archaeology and Applied Anthropology to Understand Food Loss in the American Food System", University of Arizona Bureau of Applied Research in Anthropology, Tucson, https://humwp.ucsc.edu/gleaningstories/pdf/jones_foodwaste.pdf.

Kantor, L.S. et al. (1997), "Estimating and Addressing America's Food Losses Food Review”, Food Review: The Magazine of Food Economics, vol. 20(1), http://ageconsearch.umn.edu/record/234453.

Klasen, S. (2006), "Poverty, undernutrition and child mortality: some inter-regional puzzles and their implications for research and policy", IZA Discussion Paper No. 2509, University of Göttingen and Institute for the Study of Labor (IZA) Bonn.

Milieu Centraal (undated), “Kopen op maat”, www.milieucentraal.nl/pagina?onderwerp=Kopen\%20 op\%20maat.

Miller, Y. (2003), "Recommendations for the truncation of body mass index in population data", Report No. CPAH03-0005, www.health.nsw.gov.au/surveys/other/Documents/cpah-recommendations. pdf.

Moriconi-Ebrard, F.D., D. Harre and P. Heinrichs (2016). Urbanisation dynamics in West Africa 1950-2010: Africapolis I, 2015 update, West African Studies, OECD Publishing, Paris, http://dx.doi. org/10.1787/9789264252233-en.

Nubé, M. (2001), "Confronting dietary energy supply with anthropometry in the assessment of undernutrition prevalence at the level of countries", World Development, 29(7): 1275-1289, Elsevier.

OECD/SWAC (forthcoming), Africapolis: Urbanisation dynamics in Africa 1950-2015, West African Studies, OECD Publishing, Paris.

Rutstein, S.O. (2008), “The DHS Wealth Index: Approaches for rural and urban areas”, Demographic and Health Surveys Working papers, No. 60, https://dhsprogram.com/publications/publication-wp60-working-papers.cfm.

Svedberg, P. (1999), “841 million undernourished?”, World Development, 27: 2081-2098, Elsevier.

UNICEF/MICS, Multiple Indicator Cluster Surveys (database), New York, http://mics.unicef.org.

United Nations (2017), World Population Prospects (database), UN Population Division of the Department of Economic and Social Affairs (DESA), New York, https://esa.un.org/unpd/wpp.

Van Wesenbeeck, C.F.A., M.A. Keyzer and M. Nubé (2009), “Estimation of undernutrition and mean calorie intake in Africa: methodology, findings and implications", International Journal of Health Geographics, 8(37): 1-18, http://dx.doi.org/10.1186/1476-072X-8-37.

WRAP (2007), “Understanding food waste”, Waste \& Resources Action Programme, www.wrap.org. uk/index.html. 


\section{ANNEX: ESTIMATION OF CALORIE INTAKE}

E or all age groups and for both sexes, relations between weights and calorie intake, with physical activity levels and birth rates as parameters, are estimated and published in FAO (2004b). The general structure of the relations is as follows:

$$
\text { cal }_{g, t}= \begin{cases}A_{g, t}+b_{g, t} * \text { weight }_{g, t}-c_{g, t} * \text { weight }_{g, t}{ }^{2}+\text { growth }_{g, t} & \text { for age groups 0-17 } \\ \left(b_{g, t} * \text { weight }_{g, t}+A_{g, t}\right) * P A L_{g, t} & \text { for age groups 18+ } \\ \left(b_{g, t} * \text { weight }_{g, t}+A_{g, t}\right) * P A L_{g, t}+c_{g, t} * R A T E_{g, t} & \text { for women in fertile age groups }\end{cases}
$$

where the subscript $g$ denotes gender and $t$ denotes age; $c a l_{g, t}$ is the calculated daily calorie intake by age and gender, weight $_{g, t}$ is the measured weight of the person, growth $_{g, t}$ is a parameter representing allowance for growth; $A_{g, t}, b_{g, t}, c_{g, t}$ are other given parameters, $P A L_{g, t}$ is the Physical Activity Level correction factor, and $R A T E_{g, t}$ is the birth rate by age group for women in fertile age groups. Hence, all coefficients are gender- and age-specific.

National figures for birth rates are obtained from FAO (2004a), and supposed to be equal for all women in the fertile age groups. This is a simplification, of course, but it may be warranted as this study uses only the figures to calculate nutritional requirements of mothers, as opposed to the births themselves. Growth allowances and values of the parameters $A_{g, t}, b_{g, t}, c_{g, t}$ are taken from FAO (2004b).

Since the DHS data only contain data on weights for adult females, weights for men have to be imputed, based on FAO (2004a) that provides estimates of weights of women and men of all age groups for all countries, and apply the ratio of the weight of males and females in the same age group to calculate the weight of the men. Another major factor affecting the estimation of per capita consumption by gender and age is the correction for physical activity level (PAL). The minimal correction is a factor 1.58 that corresponds to very light activity such as sleeping, sitting, and standing, and increases with the activity level. The calculations made in this study use a relatively low PAL factor, to remain on the conservative side regarding calorie intake; PAL factors are set to 1.58 for urban areas, and to 1.8 for rural, to reflect that, in general, rural work is more physically demanding than urban work.

The next step in the estimation of total calorie consumption is the calculation of rural, urban, and national average calorie intake. For this, data on the structure of the population by age group and gender is used. Using the methodology described above, an average calorie intake for sub-Saharan Africa of $2098 \mathrm{Kcal} / \mathrm{capita} /$ day is estimated. To allow comparison with estimates as presented e.g. by FAO (2017), a final step is to convert calorie intake to food availability. Food availability data refer to all food available for human consumption at retail level. This implies that food wastes occurring at retail level and food losses at household level (including foods given to pets, other animals) are included. Also, food losses that occur in institutions such as hospitals, schools, or the military, are included in estimates of food availability. At household level, in high income countries the total consumption that does not result in human intake runs into the 300-400 kcal per person per day (Kantor and Lipton, 1997; Jones, 2004; WRAP, 2007; Milieu Centraal, undated). Losses at retail level and in institutional feeding are probably larger, but reliable data are not available. As a conservative estimate, the food wastes are estimated at 200 and $100 \mathrm{kcal}$ per capita per day in urban and rural areas, respectively, with a maximum of 10 and 5 per cent, respectively, in total per capita consumption. 




\section{ALSO IN THE WEST AFRICAN PAPERS SERIES:}

Allen, T. and P. Heinrigs (2016), "Emerging Opportunities in the West African Food Economy", http://dx.doi. org/10.1787/5jlvfj4968jb-en

Lewis, K. and C. Buontempo (2016), "Climate Impacts in the Sahel and West Africa: The Role of Climate Science in Policy Making", http://dx.doi.org/10.1787/5jlsmktwjcd0-en

Gnisci, D. (2016), “Women's Roles in the West African Food System: Implications and Prospects for Food Security and Resilience", http://dx.doi.org/10.1787/5jlpl4mh1hxn-en

Staatz, J. and F. Hollinger (2016), "West African Food Systems and Changing Consumer Demands", http://dx.doi.org/10.1787/b165522b-en

Prieto Curiel, R., P. Heinrigs and I. Heo (2017), "Cities and Spatial Interactions in West Africa: A Clustering Analysis of the Local Interactions of Urban Agglomerations", http://dx.doi.org/10.1787/57b30601-en

Walther, O. (2017), "Cross-border Co-operation Networks in West Africa", http://dx.doi.org/10.1787/73298292-en

Ibrahim, I.Y. (2017), “The Wave of Jihadist Insurgency in West Africa: Global Ideology, Local Context, Individual Motivations", http://dx.doi.org/10.1787/eb95c0a9-en

Allen, T. (2017), "The cost of high food prices in West Africa", http://dx.doi.org/10.1787/c2db143f-en

Van Den Hoek, J. (2017), “Agricultural market activity and Boko Haram attacks in northeastern Nigeria”, http://dx.doi. org/10.1787/13ba9f2e-en

Walther, O. (2017), "Wars and Conflicts in the Sahara-Sahel", http://dx.doi.org/10.1787/8bbc5813-en

Elisher, S. (2018), “Defying the Odds? Nigerien Responses to Foreign and Domestic Security Challenges", https://doi. org/10.1787/104d1c6d-en

Eizenga, D. (2018), “The Unstable Foundations of Political Stability in Chad", https://doi.org/10.1787/508844d3-en

Bouchama, N., et al. (2018), "Gender Inequality in West African Social Institutions", http://dx.doi.org/10.1787/fe5ea0ca-en

Allen, T., P. Heinrigs and I. Heo (2018), "Agriculture, food and jobs in West Africa", https://doi.org/10.1787/dc152bc0-en

For more information on the series, please contact: lia.beyeler@oecd.org 